- Mouth cancer is one of the most distressing forms of cancer because of its disfiguring effects and high mortality rate.

- The large majority of people are, in some sense, aware that they can get cancer of the mouth and that smoking is a risk factor.

- Far fewer people are aware of the role of alcohol in cancer of the mouth or what to look out for in terms of early signs.

- Those at greatest risk are generally the least likely to be aware of risk factors and early signs.

- Mass media campaigns and healthcare practitioners have an important role to play in educating those at high risk about how to reduce their risk and what to look out for in terms of early signs.

\title{
Awareness of mouth cancer in Great Britain
}

\author{
R. West, ${ }^{1}$ M. N. Alkhatib, ${ }^{2}$ A. McNeill ${ }^{3}$ and R. Bedi ${ }^{4}$
}

Objective There are more than 2,000 new cases of mouth cancer each year in Britain. Early detection is important yet little is known about population awareness of this disease and ability to recognise early signs, particularly among high risk groups. This study aimed to address this issue.

Methods Data were collected by means of household survey. A total of 3,384 adults were questioned using a national probability sample. Respondents provided information on demographic characteristics, smoking status, and frequency of alcohol use. They were asked whether they had heard of mouth cancer. Their knowledge of early signs and risk factors was assessed.

Results Whereas $95.6 \%$ of respondents said they had heard of mouth cancer, their awareness of early signs was low; for example, only $33.8 \%$ recognised that white patches in the mouth were a sign. The large majority understood that smoking and chewing tobacco were risk factors (84.7\% and $80.1 \%$ respectively) but only $19.4 \%$ recognised alcohol use as a risk factor. In multiple logistic regression analyses controlling for relevant demographic factors, smokers and those with more frequent alcohol consumption were less likely to recognise early signs.

Conclusions Awareness of early signs of mouth cancer is low and lower in people who as a result of their behaviour are at higher risk. There is a need to raise awareness in those at most risk.

\section{INTRODUCTION}

In the years 1998 to 2000 an average of 5,010 new cases of oral cancer (lips, mouth and pharynx) were detected per year in the UK. ${ }^{1}$ In 2000 there were 2,073 new cases of mouth cancer. The mortality to incidence ratio is almost $40 \%$ which is higher than for breast cancer and cervical cancer. ${ }^{1}$ There is concern that the

\footnotetext{
${ }^{1 *}$ Professor of Health Psychology, Department of Epidemiology and Public Health, University College London, 2-16 Torrington Place, London WC1E 6BT; ${ }^{2}$ Research Fellow in Dental Public Health, Department of Dental Public Health, Guy's King's \& St Thomas' Dental Institute, Floor 2, Caldecot Road, Denmark Hill Campus, London SE5 9RW; ${ }^{3}$ Senior Research Fellow, Department of Epidemiology and Public Health, University College London, 2-16 Torrington Place, London WC1E 6BT; ${ }^{4}$ Professor of Dental Public Health Department of Dental Public Health, Guy's King's \& St Thomas' Dental Institute, Floor 2, Caldecot Road, Denmark Hill Campus, London SE5 9RW

${ }^{*}$ Correspondence to: Dr Robert West

Email:robert.west@ucl.ac.uk
}

\section{Refereed paper}

Accepted 16 June 2005

doi: $10.1038 /$ sj.bdj.4813197

$\odot$ British Dental Journal 2006; 200: 167-169 incidence is increasing in the young. ${ }^{2}$ Mouth cancer is largely preventable by avoiding known risk factors and national and international guidelines stress the importance of early detection. ${ }^{3}$ The main risk factors are smoking and high levels of alcohol consumption, the two acting synergistically. ${ }^{4}$ Use of oral tobacco (chewing tobacco and tobacco mixtures such as paan) has also been linked to oral cancers. ${ }^{5}$

Little is known about awareness of mouth cancer in the UK population. The most recent study involved focus groups in northern England and reported low levels of awareness in a group of older male drinkers and smokers. ${ }^{6}$ A national survey conducted in $1995^{7}$ reported low levels of awareness: 56\% had heard of mouth cancer, a much lower figure than for other cancers. The only other country that has similar data is the USA. A 1996 review of studies that had examined awareness of oral cancer (of which mouth cancer is an important subset) in the US concluded that awareness was low but the number of studies was small and few involved representative samples. ${ }^{8}$ A national survey of adults in the US in 1990 found little awareness of oral cancer: ${ }^{9}$ only $25 \%$ could identify one of the early signs. More recently, a small survey of Maryland veterans in 1998 reported that 84\% recognised tobacco use as a risk factor for oral cancer but only 39\% identified alcohol. ${ }^{10}$

Information is similarly scarce on the extent to which health professionals such as GPs or dentists raise the topic with high risk groups. A UK survey of dentists undertaken in 1991 found that $84 \%$ of respondents claimed to perform screening of the oral mucosa regularly. ${ }^{11}$ However the authors note that the response rate was only 16\%. A more recent survey of knowledge and screening practices of GP and dentists in the north east of England found knowledge levels to be high (eg of early signs and risk factors). ${ }^{12}$ However it was not clear how pro-active the clinicians were in raising the topic with patients. One study in Maryland USA found that $77 \%$ of physicians reported asking patients about risk factors for oral cancer. ${ }^{13}$

In recent years smokers in the UK have been found to be knowledgeable about the health consequences of smoking. ${ }^{14}$ Ideally individuals at greater risk of a disease would have received advice and information about this; in the case of oral cancer this is particularly important because of the possibility of early detection. The UK 1995 survey mentioned earlier found little difference in overall awareness between smokers and non-smokers but no mention was made of any difference of awareness of early symptoms. ${ }^{7}$ 


\begin{tabular}{|c|c|c|c|}
\hline & $\begin{array}{l}\text { Men } \\
\%(N)\end{array}$ & $\begin{array}{l}\text { Women } \\
\%(\mathrm{~N})\end{array}$ & $\begin{array}{l}\text { Total } \\
\%(\mathrm{~N})\end{array}$ \\
\hline Not heard of mouth cancer & $4.9(70)$ & $4.1(79)$ & $4.4(149)$ \\
\hline $\begin{array}{l}\text { GP or dentist has mentioned } \\
\text { mouth cancer }\end{array}$ & $6.6(95)$ & $7.4(144)$ & $7.1(239)$ \\
\hline GP had mentioned mouth cancer & $1.6(23)$ & $1.2(24)$ & $1.4(47)$ \\
\hline $\begin{array}{l}\text { Dentist had mentioned } \\
\text { mouth cancer }\end{array}$ & $5.5(79)$ & $6.8(132)$ & $6.3(211)$ \\
\hline $\begin{array}{l}\text { Recognised early signs of mouth cancer } \\
\text { white patches } \\
\text { red patches } \\
\text { persistent ulcer }\end{array}$ & $\begin{array}{l}31.5(453) \\
22.8(328) \\
62.2(895)\end{array}$ & $\begin{array}{l}35.5(691) \\
25.7(500) \\
69.7(1355)\end{array}$ & $\begin{array}{l}33.8(1144)^{*} \\
24.5(828)^{*} \\
66.5(2250)^{*}\end{array}$ \\
\hline $\begin{array}{l}\text { Recognised risk factors } \\
\text { smoking } \\
\text { oral tobacco use } \\
\text { drinking alcohol }\end{array}$ & $\begin{array}{l}83.3(1198) \\
79.6(1145) \\
19.2(277)\end{array}$ & $\begin{array}{l}85.8(1668) \\
80.5(1566) \\
19.4(378)\end{array}$ & $\begin{array}{l}84.7(2866)^{*} \\
80.1(2711) \\
19.4(655)\end{array}$ \\
\hline
\end{tabular}

Table 2 Results of multiple logistic regression analyses predicting mouth cancer awareness, and awareness of early signs and risk factors

\begin{tabular}{|c|c|c|c|c|c|}
\hline & Sex $^{1}$ & Age & SEG & Smoking & $\begin{array}{l}\text { Drinking } \\
\text { frequency }\end{array}$ \\
\hline $\begin{array}{l}\text { Not heard } \\
\text { of mouth } \\
\text { cancer }\end{array}$ & $\begin{array}{l}0.76 \\
(0.53-1.09)\end{array}$ & $\begin{array}{l}1.21^{* * *} \\
(1.08-1.36)\end{array}$ & $\begin{array}{l}0.83^{* * *} \\
(0.74-0.92)\end{array}$ & $\begin{array}{l}0.78^{*} \\
(0.63-0.91)\end{array}$ & $\begin{array}{l}1.60^{* *} \\
(1.09-2.36)\end{array}$ \\
\hline $\begin{array}{l}\text { GP or } \\
\text { dentist has } \\
\text { mentioned } \\
\text { mouth cancer }\end{array}$ & $\begin{array}{l}1.17 \\
(0.89-1.55)\end{array}$ & $\begin{array}{l}1.05 \\
(0.96-1.15)\end{array}$ & $\begin{array}{l}1.09^{*} \\
(1.00-1.18)\end{array}$ & $\begin{array}{l}1.02 \\
(0.74-1.40)\end{array}$ & $\begin{array}{l}1.08 \\
(0.93-1.26)\end{array}$ \\
\hline \multicolumn{6}{|c|}{ Recognised early signs of mouth cancer } \\
\hline $\begin{array}{l}\text { white } \\
\text { patches }\end{array}$ & $\begin{array}{l}1.22^{* *} \\
(1.05-1.43) \\
\end{array}$ & $\begin{array}{l}0.93^{* *} \\
(0.88-0.97)\end{array}$ & $\begin{array}{l}1.09^{* * *} \\
(1.04-1.13) \\
\end{array}$ & $\begin{array}{l}0.81^{*} \\
(0.67-0.96)\end{array}$ & $\begin{array}{l}0.97 \\
(0.90-1.05)\end{array}$ \\
\hline red patches & $\begin{array}{l}1.25^{* *} \\
(1.06-1.48)\end{array}$ & $\begin{array}{l}0.91^{* * *} \\
(0.86-0.96)\end{array}$ & $\begin{array}{l}1.12^{* * *} \\
(01.06-1.17)\end{array}$ & $\begin{array}{l}0.76^{* *} \\
(0.63-0.93)\end{array}$ & $\begin{array}{l}1.10^{*} \\
(1.00-1.20)\end{array}$ \\
\hline $\begin{array}{l}\text { persistent } \\
\text { ulcer }\end{array}$ & $\begin{array}{l}1.55^{* * *} \\
(1.33-1.81)\end{array}$ & $\begin{array}{l}0.95^{*} \\
(0.90-0.99)\end{array}$ & $\begin{array}{l}1.17^{* * *} \\
(1.11-1.22)\end{array}$ & $\begin{array}{l}0.77^{* *} \\
(0.65-0.92)\end{array}$ & $\begin{array}{l}1.11^{*} \\
(1.02-1.21)\end{array}$ \\
\hline $\begin{array}{l}\text { Recognised ris } \\
\text { smoking }\end{array}$ & $\begin{array}{l}\text { k factors } \\
1.27^{*} \\
(1.04-1.56)\end{array}$ & $\begin{array}{l}0.76^{* * *} \\
(0.72-0.81)\end{array}$ & $\begin{array}{l}1.11^{* * *} \\
(1.04-1.18\end{array}$ & $\begin{array}{l}0.78^{*} \\
(0.62-0.99) \\
\end{array}$ & $\begin{array}{l}0.97 \\
(0.87-1.07) \\
\end{array}$ \\
\hline $\begin{array}{l}\text { oral } \\
\text { tobacco use }\end{array}$ & $\begin{array}{l}1.12 \\
(0.94-1.35)\end{array}$ & $\begin{array}{l}0.79^{* * *} \\
(0.74-0.84)\end{array}$ & $\begin{array}{l}1.15^{* * *} \\
(1.09-1.22)\end{array}$ & $\begin{array}{l}0.73^{* *} \\
(0.60-0.90)\end{array}$ & $\begin{array}{l}1.05 \\
(0.96-1.16)\end{array}$ \\
\hline $\begin{array}{l}\text { drinking } \\
\text { alcohol }\end{array}$ & $\begin{array}{l}1.03 \\
(0.86-1.23) \\
\end{array}$ & $\begin{array}{l}0.86^{* * *} \\
(0.81-0.91)\end{array}$ & $\begin{array}{l}1.03 \\
(0.98-1.09) \\
\end{array}$ & $\begin{array}{l}0.73^{* *} \\
(0.59-0.90)\end{array}$ & $\begin{array}{l}1.06 \\
(0.96-1.18)\end{array}$ \\
\hline \multicolumn{6}{|c|}{$\begin{array}{l}\text { Notes: Odds ratios greater than one indicate a positive relationships and those less than one } \\
\text { indicate a negative relationship. }{ }^{1} \text { Odds ratio greater than } 1 \text { means women showed greater } \\
\text { awareness. }\end{array}$} \\
\hline
\end{tabular}

This paper reports the findings of a national survey of mouth cancer awareness. The aims were: to provide information on levels of awareness of mouth cancer, its early signs and risk factors; and to examine how far awareness, knowledge and beliefs about mouth cancer are related to respondent characteristics and especially those that place individuals at greater risk, such as smoking and drinking.

\section{METHODS}

This was a cross-sectional household survey carried out as part of the National Statistical Office Omnibus series in October and November 2001. Each month, the Omnibus survey aims to interview 1,800 individuals aged 16 or over in private households. A sample of 100 postal sectors is selected, stratified by region, the proportion of households renting from local authorities (public housing) and socio-economic group. Postal sectors are selected with a probability proportionate to size and within each sector 30 addresses are randomly selected. Within households with more than one adult member one person aged over 16 is selected using random number tables. The interviewer then tries to interview that person. For estimating percentages of the population falling into particular response categories the data may be weighted to control for the fact that individuals in larger households are under-represented. However in practice this made very little difference with regard to the variables of interest and would have caused difficulties for statistical comparisons across subgroups. Therefore unweighted data were used.

Six thousand households were selected resulting in a final sample of 3,384 households. After ineligible household were excluded (eg businesses or empty properties) the effective response rate was $65 \%$ for the October wave and $62 \%$ for the November wave.

Interviews were carried out face-to-face by trained interviewers. Advance letters were sent to all addresses. The interviewer made at least three calls at the selected addresses at different times of day unless a refusal had been made beforehand in response to the advance letter.

The interviews collected information on age, gender, socioeconomic status, marital status and ethnic group of respondents. Respondents were also asked whether they smoked cigarettes and their frequency of drinking alcohol. With regard to the topic of interest the following questions were asked: whether they had heard of mouth cancer; whether their GP and/or dentist had spoken to them about mouth cancer; for each of a set of symptoms (painless white patches in the mouth; painless red patches in the mouth; a sore or ulcer that does not go away) whether these could be an early sign of mouth cancer; for each of a set of putative risk factors (smoking cigarettes; chewing tobacco; drinking alcohol) whether it could increase a person's chances of getting mouth cancer.

The omnibus surveys whose data are reported in this paper are subject to ethical approval in accordance with the Helsinki Convention.

\section{RESULTS}

The unweighted sample was made up of $42.5 \%(\mathrm{~N}=1,439)$ men and $57.5 \%(\mathrm{~N}=1,945)$ women. The mean (SD) age was 49.9 years (18.86); 32.4\% $(\mathrm{N}=1,097)$ were in 'semi-routine or routine' occupations; 89.3\% ( $\mathrm{N}=3,022)$ were white British; 55.0\% ( $\mathrm{N}=1860)$ were married or cohabiting; $25.6 \%(\mathrm{~N}=866)$ were smokers; $13.1 \%(\mathrm{~N}=443)$ drank alcohol every day or almost every day, $50.6 \%(\mathrm{~N}=1,710)$ drank less often than this but at least once a week; $16.4 \%(\mathrm{~N}=555)$ drank 'every couple of months'; $19.9 \%(N=675)$ drank once or twice a year or less.

Only 4.4\% said that they had not heard of mouth cancer (Table 1). However, awareness of the early signs was low except for persistent ulcers. There was high awareness that smoking and chewing tobacco could cause mouth cancer but only 19.4\% recognised alcohol as a risk factor. Only 7.1\% reported that their dentist or GP had spoken to them about mouth cancer.

Respondents who had not heard of mouth cancer were more likely to be older, of lower occupational status, non-smokers and likely to drink more frequently (Table 2). In general, individuals at greater risk of mouth cancer by virtue of age or smoking were less likely to be aware of its early signs but more frequent drinkers were more likely to recognise the early signs (Table 2). Recognition of smoking and mouth tobacco use as risk factors was higher related to being female, young, higher occupational status, and being a non-smoker (Table 2). Recognition of drinking alcohol as a risk factor was associated with being younger and not smoking (Table 2). In addition, individuals with lower occupational status were less likely to recall their GP or dentist having discussed the topic with them. 


\section{DISCUSSION}

Based on the findings of this survey, it appears that the large majority of the British population are aware of mouth cancer at some level. However, awareness of early signs was low as was awareness of alcohol use as a risk factor. Very few respondents recalled their GP or dentist having mentioned mouth cancer. Individuals who were at greater risk of mouth cancer by virtue of age and drinking frequency showed lower awareness but smokers showed higher awareness of the disease. Awareness of early signs showed a slightly different pattern with smokers being less likely to recognise these while more frequent drinkers were more likely to do so. Smokers were also less likely to recognise that smoking is a risk factor. Respondents with lower occupational status were less likely to say that their GP had raised the topic with them.

Awareness of mouth cancer was considerably higher than that found in a similar UK survey in $1995^{7}$ but awareness of risk factors and early signs was similar. Moreover, there was no sign of improvement in the rates of GP or dentist advice on the topic. The increased awareness could be due to a number of factors including the media attention given to oral cancer awareness week.

The failure of most respondents, and particularly those at high risk to recognise the common early warning signs, means that it is likely that many pre-cancerous lesions are failing to be recognised as such by smokers. This in turn suggests that opportunities to avert invasive cancers are being missed.

The fact that smokers were less likely to recognise smoking as a risk factor than non-smokers, even controlling for other variables such as occupational status, could arise because smokers are less willing to accept that their behaviour carries risk in general, or it could be that individuals who recognise the risks of smoking are more likely to stop. However, neither of these seems likely because smokers in the UK do not differ from non-smokers in terms of perception of smoking as a cause of fatal diseases in general. ${ }^{14}$ Also, in this survey smokers were more likely to be aware of mouth cancer as a disease than were non-smokers. One possible explanation is that, whereas with the better known smoking-related diseases such as lung cancer, the exposure of smokers to information on this overrides a tendency to ignore unwelcome information, in the case of mouth cancer this is not the case because the frequency of exposure to information is much less.

As with all surveys, this study is limited by the fact that it relies on self report. With knowledge and belief items there are no objective criteria against which responses could be validated, but the items have been used in previous national surveys. The item that may be most susceptible to bias is the one relating to GP and dentist advice. It is possible that many respondents had received such advice but did not remember it. However, the fact that they could not remember it suggests that it was not sufficiently salient and the effect remains the same. Another limitation relates to the wording of the questions. Different wordings and different response formats can give different results. In all the questions reported here, respondents only had to choose a response from a list and this would be expected to overestimate knowledge and awareness. Thus it is possible that the awareness of early signs was even lower than reported.

Whereas the risk of mouth cancer is present with any amount of smoking, moderate levels of alcohol consumption may not place individuals at risk. In this study, respondents were only asked about drinking frequency. The fact that more frequent drinkers were less likely to be aware of mouth cancer does not necessarily mean that those at higher risk were less aware. Future studies should include standard quantity-frequency measures of alcohol consumption to examine this more fully.

This study focused on 'mouth' cancer because the broader term 'oral cancer' may not be recognised by respondents. It would be useful in future to include other forms of oral cancer including the lips and pharynx.

This study indicates that a high proportion of people declare that they are aware of mouth cancer but there is far less awareness of the risk factors. In particular, smokers need to be better educated about their personal risks and the early signs of disease. GPs and dentists could play a much greater role in this. This could be incorporated into routine advice about smoking and oral tobacco use. However, public information campaigns such as oral cancer awareness week can also play an important role.

\section{What this paper adds}

This paper provides the most up-to-date information available on mouth cancer awareness in the UK and the first analysis in any country which shows that awareness is lower in individuals at higher risk because of their lifestyles, controlling for social and demographic variables.

\section{Policy implications}

Given the importance of early detection, it is essential for people to be better educated about risk factors and early signs of mouth cancer. GPs, dentists and mass media campaigns all have a role to play in this.

\section{Competing interest statement}

Robert West has undertaken research and consultancy for and received travel funds and hospitality from manufacturers of smoking cessation medications. Ann McNeill has received travel funds and hospitality from manufacturers of smoking cessation medications.

1. Office of National Statistics. Cancer Statistics Registrations. London: ONS, 2003.

2. Llewellyn $C D$, Linklater $\mathrm{K}$, Bell J et al. An analysis of risk factors for oral cancer in young people: a case-control study. Oral Oncol 2004; 40: 304-313.

3. Johnson N W. Aetiology and risk factors for oral cancer. In Dunitz M (Ed). A textbook of oral cancer. pp 33-75. London, 2003.

4. Johnson N. Tobacco use and oral cancer: a global perspective. J Dent Educ 2001; 65: 328-339

5. Critchley J A, Unal B. Health effects associated with smokeless tobacco: a systematic review. Thorax 2003; 58: 435-443.

6. Lowry R J, Craven M A. Smokers' and drinkers' awareness of oral cancer: a qualitative study using focus groups. Br Dent J 1999; 187: 668-670

7. Warnakulasuriya K A, Harris C K, Scarrott D M et al. An alarming lack of public awareness towards oral cancer. Br Dent J 1999; 187: 319-322.

8. Horowitz A M, Goodman H S, Yellowitz J A, Nourjah P A. The need for health promotion in oral cancer prevention and early detection. J Public Health Dent 1996 56:319-330.

9. Horowitz A M, Nourjah P, Gift H C. US adult knowledge of risk factors and signs of oral cancers: 1990. JAm Dent Assoc 1995; 126: 39-45.

10. Canto M T, Horowitz A M, Goodman H S et al. Maryland veterans' knowledge of risk factors for and signs of oral cancers and their use of dental services. Gerodontology 1998; 15: 79-86.

11. Warnakulasuriya K A Johnson N W. Dentists and oral cancer prevention in the UK: opinions, attitudes and practices to screening for mucosal lesions and to counselling patients on tobacco and alcohol use: baseline data from 1991. Oral Dis 1999; 5: 10-14.

12. Greenwood M, Lowry R J. Primary care clinicians' knowledge of oral cancer: a study of dentists and doctors in the North East of England. Br Dent J 2001; 191: 510-512.

13. Canto M T, Horowitz A M, Drury T F, Goodman H S. Maryland family physicians' knowledge, opinions and practices about oral cancer. Oral Oncol 2002; 38: 416-424.

14. Lader D, Meltzer H. Smoking related attitudes and behaviour. London: Office of National Statistics, 2003. 